\title{
Choline by magnetic spectroscopy and dynamic contrast enhancement curve by magnetic resonance imaging in neoadjuvant chemotherapy for invasive breast cancer
}

\author{
YORIKO MURATA, NORIHIKO HAMADA, KEI KUBOTA, KANA MIYATAKE, \\ MICHIKO TADOKORO, YUKO KATAOKA, HIRONOBU UE, KAZUHIRO TSUZUKI, \\ SHINJI KARIYA, AKIHITO NISHIOKA and YASUHIRO OGAWA
}

Department of Radiology, Kochi Medical School, Kochi University, Nankoku, Kochi 783-8505, Japan

Received June 9, 2008; Accepted October 7, 2008

DOI: $10.3892 / \mathrm{mmr} 00000059$

\begin{abstract}
This study investigated the relationship between choline by magnetic resonance spectroscopy (MRS) and late enhancement curves by dynamic magnetic resonance imaging (DMRI) in determining therapeutic response to neoadjuvant chemotherapy (NAC) among invasive breast cancer patients. Subjects comprised 21 women (22 breasts) with biopsyconfirmed invasive breast cancer (mean age 54 years) who underwent MRS with choline and gadolinium-enhanced DMRI at $1.5 \mathrm{~T}$ before and after NAC. Choline signals on MRS were classified into 2 patterns: choline-positive or cholinenegative, while late enhancement curves were classified as 'plateau' or 'washout' (type A), or 'persistent' (type B) according to the consensus of 2 radiologists. Maximum tumor diameters and clinical tumor reduction rates were assessed by MRI. Before NAC, choline-positive results were found in all 22 tumors, 21 of which were type A and 1 of which was type B. After NAC, a change from choline-positive to cholinenegative was observed with MRS in 11 tumors, while another 11 remained choline-positive. According to DMRI, enhancement curves changed from type A to type B in 14 tumors, remained type $A$ in 7 tumors, and remained type $B$ in 1 tumor. Tumor reduction rates were significantly greater for cholinenegative tumors than for choline-positive tumors after NAC $(\mathrm{p}=0.0115)$. Following NAC, no significant correlation was noted between enhancement curves and reduction rates $(\mathrm{p}=0.1210)$, although a significant correlation was noted between enhancement curves and choline signals $(\mathrm{p}=0.0014)$. Changes in choline signals as noted using MRS might offer advantages over changes in enhancement curves by DMRI when evaluating response to NAC in terms of the tumor reduction rate in invasive breast cancer.
\end{abstract}

Correspondence to: Dr Yoriko Murata, Department of Radiology, Kochi Medical School, Kochi University, Nankoku, Kochi 783-8505, Japan

E-mail: muratay@kochi-u.ac.jp

Key words: breast cancer, magnetic resonance imaging, spectroscopy, dynamic enhancement curve, neoadjuvant chemotherapy

\section{Introduction}

Among conventional modalities such as ultrasonography, mammography and computed tomography (1-3), magnetic resonance imaging (MRI) has priority for the detection of breast cancer and for the evaluation of breast cancer response to neoadjuvant chemotherapy (NAC) (4-11). Enhancement curves by dynamic MRI (DMRI) are known to be useful for detecting or monitoring breast cancer $(4,12,13)$. In addition to MRI, magnetic resonance spectroscopy (MRS) is becoming increasingly attractive for the detection or monitoring of breast cancer (14-24). MRS detects elevated levels of cholinecontaining compounds in breast cancer tissue, which yield a signal at a chemical shift of $3.2 \mathrm{ppm}$ (25). Choline by MRS and enhancement curves by DMRI represent common methods for dealing with non-morphological diagnostic parameters. The present study therefore assessed the correlation between MRS and enhancement curves from DMRI in determining response to NAC.

\section{Materials and methods}

Patients. The present study was performed at our institution between January 2007 and Feburary 2008. Subjects comprised 21 patients with invasive ductal breast carcinoma (unilateral $\mathrm{n}=20$; bilateral $\mathrm{n}=1$ ) diagnosed by ultrasonography-guided fine needle biopsy. Mean subject age was 54 years (range 40-67 years).

Neoadjuvant chemotherapy. NAC was performed with the informed consent of all patients. Basic NAC comprised 4 courses of epirubicin at $100 \mathrm{mg} / \mathrm{m}^{2}$ and cyclophosphamide at $600 \mathrm{mg} / \mathrm{m}^{2}$ (EC). In 5 patients with tumors beyond stage IIIA, 6 courses of EC were administered.

MRI examination. MRS and DMRI examinations were performed with the subject prone on a 1.5-T unit (Signa HD x 1.5; GE Healthcare, USA) using a breast coil both before and after full courses of EC. DMRI was performed using axial T1weighted first three-dimensional spoiled gradient recall echo sequence (VIBRANT, volume imaging for breast assessment) [repetition time (TR), $6.9 \mathrm{msec}$; echo time (TE), $3.4 \mathrm{msec}$; flip angle, $10^{\circ}$; field of view, $30 \times 30 \mathrm{~cm}$; matrix, $384 \times 320$; slice 


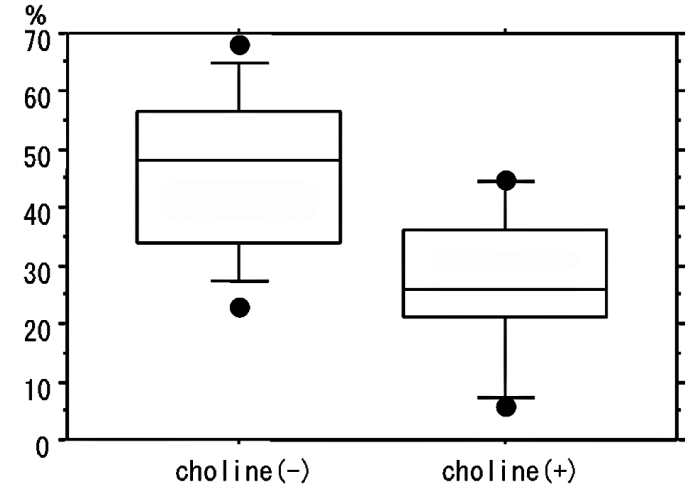

Figure 1. Choline signal after NAC and tumor reduction rate.

Table I. Choline signals and enhancement patterns after NAC.

\begin{tabular}{lcr}
\hline & \multicolumn{2}{c}{ Enhancement patterns } \\
\cline { 2 - 3 } & Type A & Type B \\
\hline Choline-positive & 7 & 4 \\
Choline-negative & 0 & 11 \\
\hline
\end{tabular}

thickness, $5 \mathrm{~mm}$; space, $0 \mathrm{~mm}$ ] obtained before and after intravenous administration of gadopentate dimeglumine (GdDTPA) at $0.1 \mathrm{mmol} / \mathrm{kg}$. Contrast agent was injected at $2 \mathrm{ml} /$ sec (Gd-DTPA $1 \mathrm{mmol} / \mathrm{sec})$. The contrast bolus was followed by a 30-ml saline flush. Single-voxel MRS (BREASE, breast spectroscopic examination) using an $8-\mathrm{cm}^{3}$ voxel size was performed on all patients (TR, $2000 \mathrm{msec}$; TE, $155 \mathrm{msec}$ ). MRS was performed after DMRI as the visibility of tumors was clearly improved on contrast-enhanced images.

MRS and DMRI data analysis. Choline signals by MRS were classified as 'positive' or 'negative' according to the consensus of 2 radiologists. Late enhancement curves were classified as 'plateau' or 'washout' (type A) or 'persistent' (type B), again with the consensus of 2 radiologists.

Tumor reduction rate. Maximum tumor diameter was measured on enhanced MRI before and 2 weeks after the fourth administration of EC chemotherapy. The tumor reduction rate was calculated as: [(maximum tumor diameter before chemotherapy - maximum tumor diameter after chemotherapy)/ maximum tumor diameter before chemotherapy] x 100 .

Statistical analysis. Data were analyzed using the MannWhitney U-test. Values of $\mathrm{p}<0.005$ were taken to indicate statistical significance.

\section{Results}

Before NAC, choline-positive results were noted in all 22 tumors, while enhancement curves were type A in 21 tumors and type B in 1 tumor. With NAC, a change from choline-

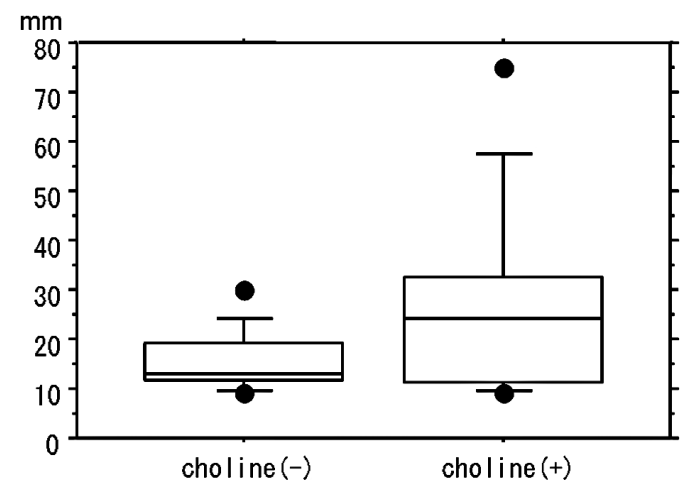

Figure 2. Choline signal and maximum tumor diameter after NAC.

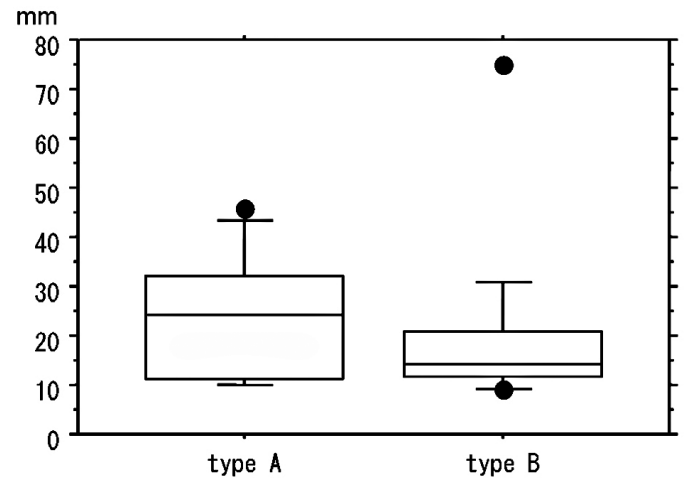

Figure 3. Enhancement pattern and maximum tumor diameter after NAC.

positive to choline-negative was observed in 11 tumors, while another 11 remained choline-positive. In the enhancement curves, a change from type A to type B was seen in 14 tumors, while 7 tumors remained type A and 1 remained type B. After NAC, all 11 choline-negative tumors and 4 of the 11 choline-positive tumors displayed type B enhancement curves. The remaining 7 choline-positive tumors showed type A enhancement. Tumor reduction rates were significantly greater for choline-negative tumors than for choline-positive tumors after NAC (negative 46.4\%; positive 27.7\%; p=0.0115; Fig. 1). No significant correlations were found between choline and tumor diameter after NAC (positive $27.5 \mathrm{~mm}$; negative $15.5 \mathrm{~mm}$; $\mathrm{p}=0.1150$; Fig. 2). A significant correlation was identified between enhancement patterns and choline results after NAC ( $\mathrm{p}=0.0014)$ (Table I). However, no significant relationship was apparent between enhancement patterns after NAC and reduction rates (type A 28.9\%; type B 40.8\%; $\mathrm{p}=0.1210$; Fig. 3) or between enhancement patterns and tumor diameter after NAC (type A $23.0 \mathrm{~mm}$; type B $21 \mathrm{~mm}$; $\mathrm{p}=0.3782$; Fig. 4). No significant correlation was noted between enhancement curves and reduction rate or tumor diameter for the 11 choline-positive tumors after NAC (reduction rate: type A 28.9\%; type B 25.8\%; p=0.7768; Fig. 5) (diameter: type A $23.6 \mathrm{~mm}$; type B $34.0 \mathrm{~mm}$; $\mathrm{p}=0.8501$; Fig. 6). Tumor reduction rate did not differ according to the number of courses of chemotherapy (4 courses $35.8 \%$; 6 courses $41.2 \%$; $=0.5328$ ). Fig. 7 shows a representative patient with right breast cancer that exhibited a type A 


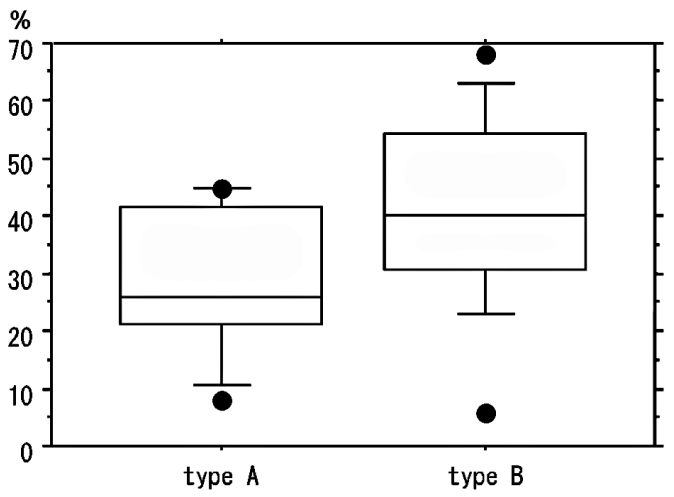

Figure 4. Enhancement pattern after NAC and tumor reduction rate.

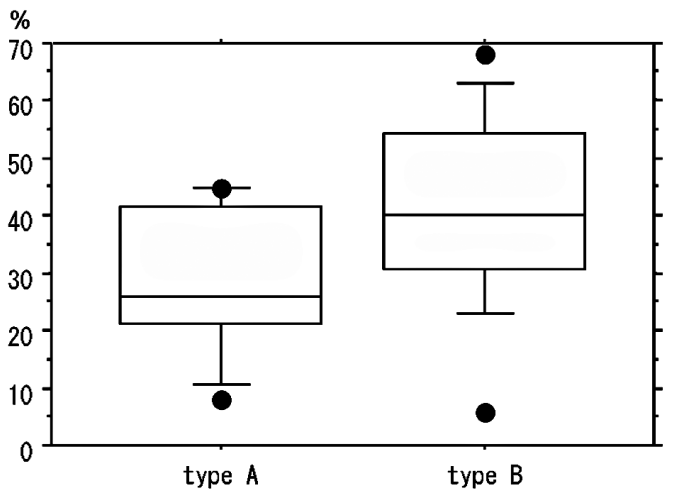

Figure 5. Enhancement pattern and maximum tumor diameter in 11 cholinepositive tumors after NAC.

enhancement pattern and positive choline peak before NAC, and a type B enhancement pattern and negative results for choline after NAC. Tumor reduction rate was $45.9 \%$.

\section{Discussion}

The present findings indicate that MRS may enable the simple evaluation of response to NAC more effectively than enhancement curves from DMRI. Although the mean tumor reduction rate tended to be greater for type $B$ than for type $A$ tumors after NAC, no significant difference in reduction rate was observed between the 2 types of enhancement curves.

Changes in choline signal are reportedly useful for evaluating response to treatment in many types of tumors (26-28). Choline elevation has also been confirmed to be a sensitive and specific marker of response to treatment for breast cancer $(17,20)$. However, the utility of MRS in determining breast cancer response to NAC has not previously been established. The precise mechanisms by which neoplastic tissues exhibit elevated choline levels remain unclear (20). Increased levels of phosphocholine, the primary metabolite responsible for choline signals in neoplastic tissue, may result from increased membrane synthesis by replicating cells (20). Choline signals may reflect a change in the balance between the biosynthetic and catabolic pathways, in which choline serves as both a precursor and a catabolite (29).

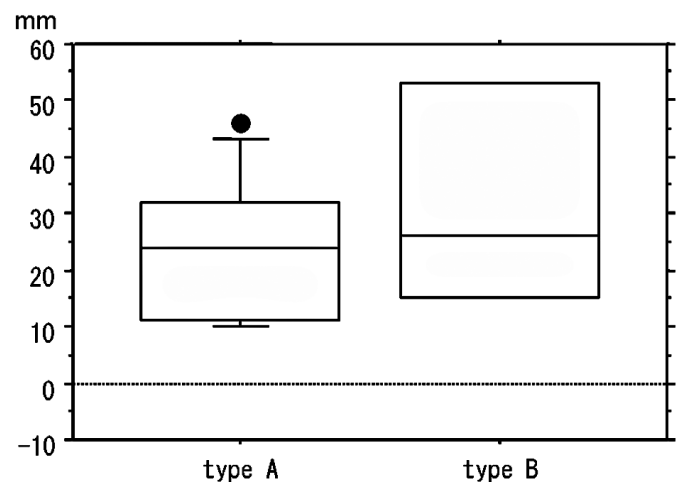

Figure 6. Enhancement pattern and tumor reduction rate in 11 choline-positive tumors after NAC.

Conversely, DMRI is already established for the evaluation of breast cancer $(4,10,17)$. Late enhancement curves are known to be useful in diagnosing and differentiating breast cancers from benign tumors $(4,13,16,30)$. Malignant tumors show specific washout or plateau enhancement patterns, while benign tumors show a persistent pattern $(10,30)$. Changes in enhancement curves have been reported after chemotherapy for breast cancer $(4,16)$.

MRS and enhancement curves, which do not provide morphological information, might be of only limited use in surgical planning, but can provide important information concerning changes in tumor characteristics in terms of vascularity or metabolism after NAC. The current results indicate that a multiparametric approach using MRS and enhancement patterns is likely to prove useful for determining therapeutic response to breast cancer.

A significant correlation was noted between choline and enhancement curves after NAC. Without a doubt, all choline-negative tumors after NAC demonstrated the type B enhancement. However, 4 of the 11 tumors that were cholinepositive after NAC also demonstrated the type B enhancement. No significant correlation existed between enhancement curves and decreased tumor diameter or reduction rate in the 11 tumors that remained choline-positive. Changes in choline within $24 \mathrm{~h}$ of first or second treatment have been reported to be predictive markers of breast cancer response to NAC $(17,20)$. Changes in choline concentration after the second treatment may represent an indicator for predicting response to NAC, rather than pharmacokinetic parameters (17). Choline metabolism reportedly correlates with angiogenesis activity before NAC (19), and chemotherapy can be considered to induce decreased choline metabolism and angiogenic activity. However, the balance between choline metabolism and angiogenesis may become confused during chemotherapy until tumors respond sufficiently in size and activity. As well, the correlation between choline metabolism and angiogenesis after NAC might be complicated.

The present study displayed several limitations. First, the patient population was small. Nevertheless, and though additional studies with larger populations are necessary for further assessment, some significant results emerged. Second, peak choline was only categorized into 2 types, positive and negative. The quantitative assessment of the choline peak 
$\mathbf{a}$

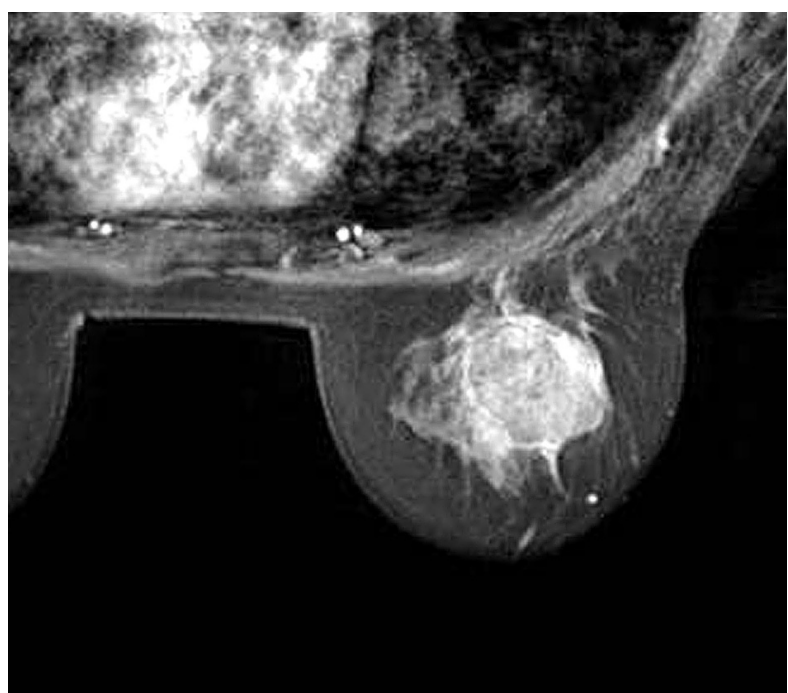

b-1

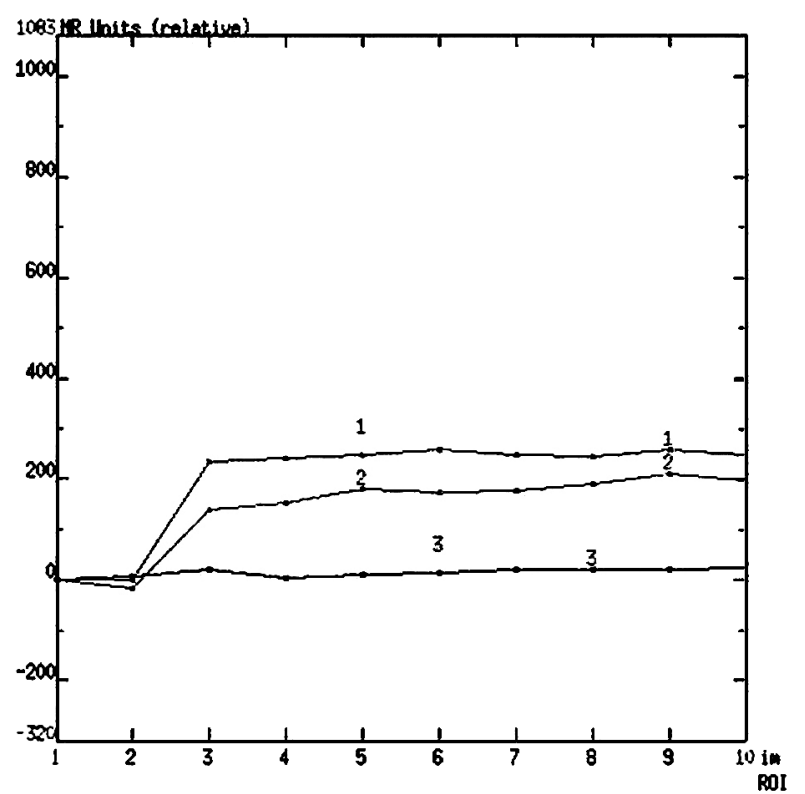

b-2

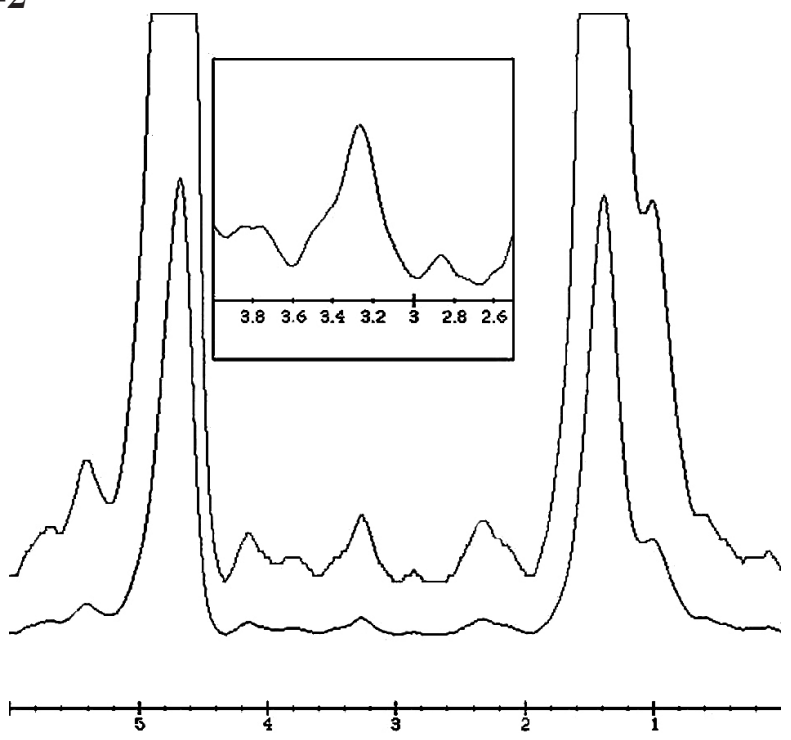

c

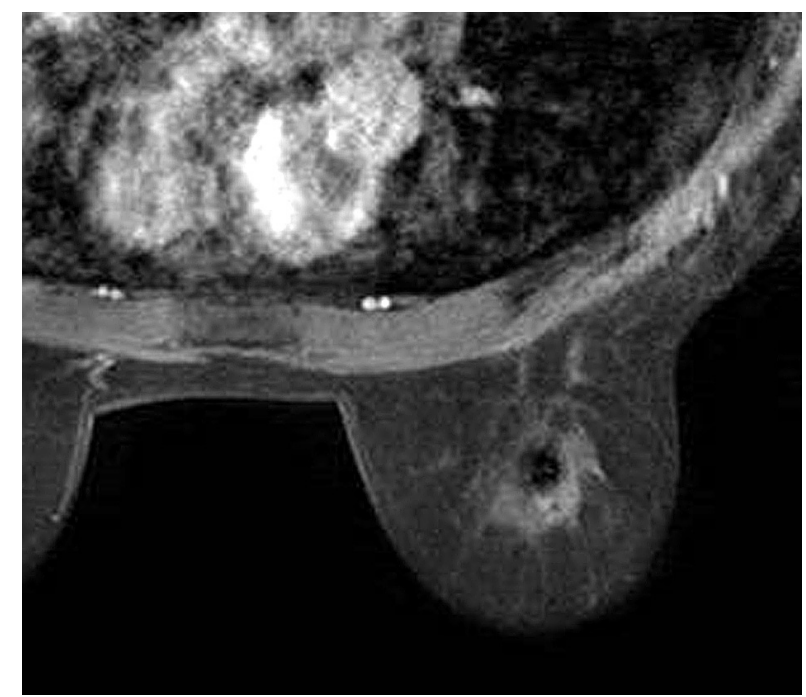

d-1

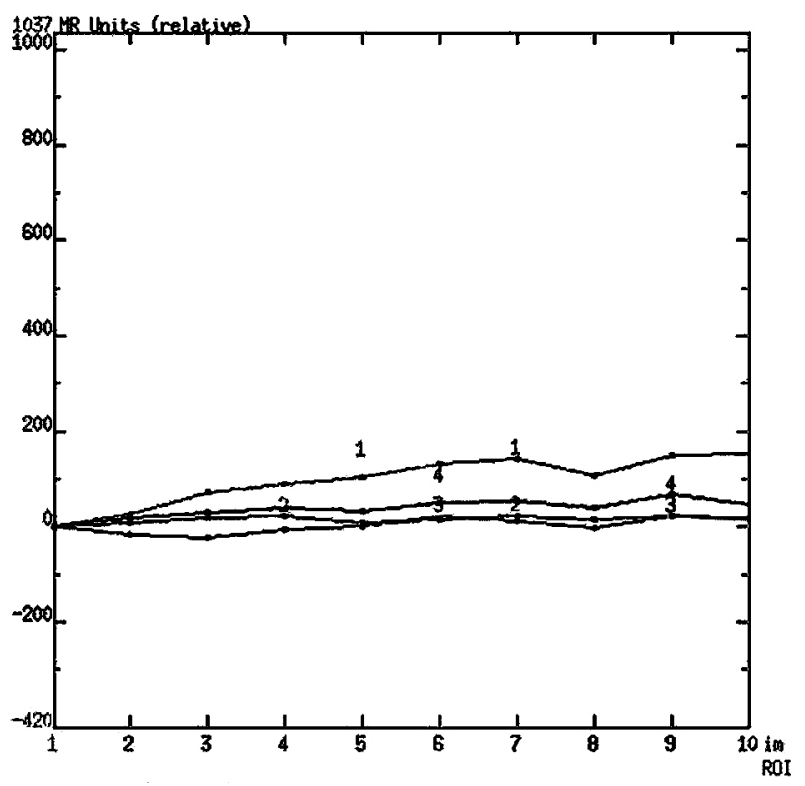

d-2

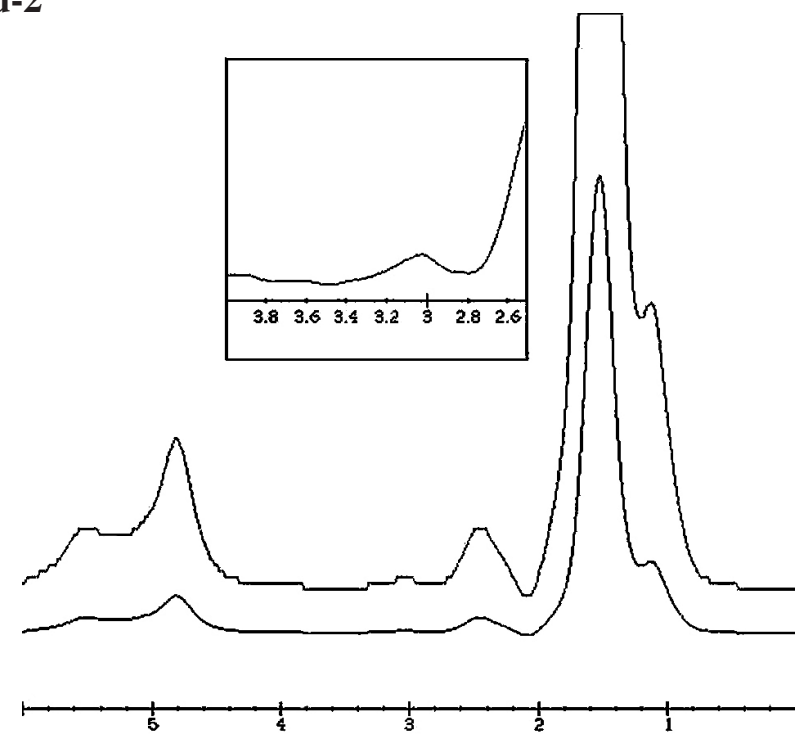

Figure 7. A 59-year-old woman with right breast cancer and a clinical tumor reduction rate of $45.9 \%$ (maximum diameter 30.1-16.3 mm) with NAC. (a) Enhancement curves by DMRI of the tumor before NAC. (b) The tumor displayed type B enhancement curves (b-1) and positive choline signals (b-2) before NAC. (c) Enhancement curves by DMRI of the tumor after NAC. (d) The tumor displayed type B enhancement curves (d-1) and negative choline signals (d-2) after NAC. 
remains problematic. Third, the $8-\mathrm{cm}^{3}$ single voxel MRS used offers limited spatial coverage. Partial volume effects might be excluded using an $8-\mathrm{cm}^{3}$ voxel MRS. Reductions in tumor size might affect choline detection by MRS, as tumors shrink after NAC. However, the current results do not contradict the findings of previous studies that have demonstrated that the choline peak is related more to the malignant nature than to the size of the tumor (21). Finally, MRS in this study was performed after DMRI. Adverse effects impacting the detection of choline signals remain controversial $(14,28)$. MRS after contrast administration was useful in improving the detectability of the shrinking tumor after NAC.

In conclusion, MRS using a choline peak, when classified simply as positive or negative, may prove far more useful than late enhancement curves for monitoring the response of breast cancer to NAC in terms of tumor reduction rate.

\section{Acknowledgements}

The authors thank Takafumi Akagi, Shin Yaogawa, Hiroaki Yasunami and Kazuo Morio for technical assistance.

\section{References}

1. Kubota K, Ogawa Y, Nishioka A, Kariya S, Itoh S, Murata Y, Hamada N, Maeda H and Tanaka Y: Diagnostic accuracy of mammography, ultrasonography and magnetic resonance imaging in the detection of intraductal spread of breast cancer following neoadjuvant chemotherapy. Oncol Rep 17: 915-918, 2007.

2. Ogawa Y, Nishioka A, Kubota K, Kariya S, Yoshida S, Maeda H, Tanaka Y, Moriki T and Tochika N: CT findings of breast cancer with clinically complete response following neoadjuvant chemotherapy-histological correlation: Oncol Rep 10: 1411-1415, 2003.

3. Akashi-Tanaka S, Fukutomi T, Watanabe T, Katsumata N, Nanasawa T, Matsuo K, Miyakawa K and Tsuda H: Accuracy of contrast-enhanced computed tomography in the prediction of residual breast cancer after neoadjuvant chemotherapy. Int J Cancer 96: 66-73, 2001

4. Tsuboi N, Ogawa Y, Inomata T, Yoshida D, Yoshida S, Moriki T and Kumon M: Changes in the findings of dynamic MRI by preoperative CAF chemotherapy for patients with breast cancer of stage II and III: Pathologic correlation. Oncol Rep 6: 727-732, 1999.

5. Balu-Maestro C, Chapellier C, Bleuse A, Chanalet I, Chauvel C and Largiller R: Imaging in evaluation of response to neoadjuvant breast cancer treatment benefits of MRI. Breast Cancer Res Treat 72: 145-152, 2002.

6. Abraham DC, Jones RC, Jones SE, Cheek JH, Peters GN, Knox SM, Grant MD, Hampe DW, Savino DA and Harms SE: Evaluation of neoadjuvant chemotherapeutic response of locally advanced breast cancer by magnetic resonance imaging. Cancer 78: 91-100, 1996.

7. Weatherall PT, Evans GF, Metzger GJ, Saborrian MH and Leith AM: MRI vs. histopathologic measurement of breast cancer following chemotherapy: comparison with X-ray mammography and palpation. J Magn Reson Imaging 13: 868-875, 2001.

8. Gilles R, Guinebretiere J-M, Toussaint C, Spielman M, Rietjen M, Petit J-Y, Contesso G, Masselo J and Vael D: Locally advanced breast cancer: contrast-enhanced subtraction MR imaging of response to preoperative chemotherapy. Radiology 191: 633-638, 1994.

9. Murata Y, Ogawa Y, Yoshida S, Kubora K, Itoh S, Fukumoto M, Nishioka A, Moriki T, Maeda H and Tanaka Y: Utility of initial MRI for preceding extent of residual disease after neoadjuvant chemotherapy: Analysis of 70 breast cancer patients. Oncol Rep 12: 1257-1262, 2004.

10. Kuhl CK and Schild HH: Dynamic image interpretation of MRI of the breast. J Magn Reson Imaging 12: 965-974, 2000.

11. Hamada N, Ogawa Y, Nishioka A, Kariya S, Terashima M, Yoshida S, Tanaka Y and Inomata T: An elderly patient with DCIS of the breast effectively treated with toremifene alone. Oncol Rep 9: 475-478, 2002.
12. Siegmann KC, Muller-Schimpfle M, Schick F, Remy CT, Fersis N, Ruck P, Gorriz C and Claussen CD: MR imaging-detected breast lesions: histopathologic correlation of lesion characteristics and signal intensity data. AJR Am J Roentgenol 178: 1403-1409, 2002.

13. Kuhl CK, Shild HH and Morakkabati N: Dynamic bilateral contrast-enhanced MR imaging of the breast: trade-off between spatial and temporal resolution. Radiology 236: 789-800, 2005.

14. Yeung DKW, Cheung HS and Tse GMK: Human breast lesions: characterization with contrast-enhanced in vivo proton MR spectroscopy - initial results. Radiology 200: 40-46, 2001.

15. Bolan PJ, Nelson MT, Yee D and Garwood M: Imaging in breast cancer: magnetic resonance spectroscopy. Breast Cancer Res 7: 149-152, 2005.

16. Yeung DKW, Yang WT and Tse GMK: Breast cancer: in vivo proton MR spectroscopy in the characterization of histopathologic observations in axillary node metastases. Radiology 225: 190-197, 2002.

17. Manton DJ, Chaturvedi A, Hubbard A, Lind MJ, Lowry M, Maraveyas A, Pickles MD, Tozer DJ and Turnbull LW: Neoadjuvant chemotherapy in breast cancer: early response prediction with quantitative MR imaging and spectroscopy. Br J Cancer 94: 427-435, 2006

18. Jacobs MA, Barker PB, Argani P, Ouwerkerk R, Bhujwalla ZM and Bluemke DA: Combined dynamic contrast enhanced breast MR and proton spectroscopic imaging: a feasibility study. J Magn Reson Imaging 21: 23-28, 2005.

19. Su MY, Baik HM, Yu HJ, Chen JH, Mehta RS and Nalcioglu O: Comparison of choline and pharmacokinetic parameters in breast cancer measured by MR spectroscopic imaging and dynamic contrast enhanced MRI. Technol Cancer Res Treat 5: 401-410, 2006.

20. Meisamy S, Bolan PJ, Baker EH, Bliss RL, Gulbahce E, Everson LI, Nelson MT, Emory TH, Tuttle TM, Yee D and Garwood M: Neoadjuvant chemotherapy of locally advanced breast cancer: predicting response with in vivo $1 \mathrm{H}$ MR spectroscopy - a pilot study at 4T. Radiology 233: 424-431, 2004.

21. Bartella L, Morris EA, Dershaw DD, Liberman L, Thakur SB, Moskowitz C, Guido J and Huang W: Proton MR spectroscopy with choline peak as malignancy marker improves positive predictive value for breast cancer diagnosis: preliminary study. Radiology 239: 686-692, 2006.

22. Baek HM, Yu HJ, Chen JH, Nalcioglu O and Su MY: Quantitative correlation between (1)H MRS and dynamic contrast-enhanced MRI of human breast cancer. Magn Reson Imaging 26: 523-531, 2007.

23. Tse GM, Cheung HS, Pang LM, Chu WCW, Kung FYL and Yeung DKW: Characterization of lesions of the breast with proton MR spectroscopy: comparison of carcinomas, benign lesions, and phyllodes tumors. AMJ Am J Roengenol 181: 1261-1272, 2003.

24. Jagannathan NR, Kumar M, Seenu V, Coshic O, Dwivedi SN, Julka PK, Srivastava A and Rath GK: Evaluation of total choline from in-vivo volume localized proton MR spectroscopy and its response to neoadjuvant chemotherapy in locally advanced breast cancer. Br J Cancer 8: 1016-1022, 2001.

25. Mackinnon WB, Barry PA, Malycha PL, Gillett DJ, Russell P, Lean CL, Doran ST, Barraclough BH, Bilous M and Mountford CE: Fine-needle biopsy specimens of benign breast lesions distinguished from invasive cancer ex vivo with proton MR spectroscopy. Radiology 204: 661-666, 1997.

26. Herminghaus S, Pilatus U, Moller-Hartmann W, Raab P, Lanfermann H, Scholte W and Zanella FE: Increased choline levels coincide with enhanced proliferative activity of human neuroepithelial brain tumors. NMR Biomed 15: 385-392, 2002.

27. Therasse P, Arbuck SG, Eisenhauer EA, Wanders J, Kaplan RS, Rubinstein L, Verweij J, Glabbeke V, van Oosterom AT, Christian MC and Gwyther SG: New guidelines to evaluate the response to treatment in solid tumors. J Nat Cancer Inst 92: 205-216, 2000

28. Sijens PE, van den Bent MJ, Nowark PJ, van Dijk P and Oudkerk $\mathrm{M}: 1 \mathrm{H}$ chemical shift imaging reveals loss of brain tumor choline signal after administration of Gd contrast. Magn Reson Med 37: 222-225, 1997.

29. Podo F: Tumour phospholipid metabolism. NMR Biomed 12: 413-439, 1999.

30. Orel SG: Differentiating benign from malignant enhancing lesions identified at MR imaging of the breast: Are time-signal intensity cures an accurate predictor? Radiology 211: 5-7, 1999. 
